\title{
QUALIDADE FISIOLÓGICA DE SEMENTES ESVERDEADAS DE SOJA TRATADAS COM BIOESTIMULANTE
}

\author{
Mariana Zampar Toledo ${ }^{1}$, Caíque Araujo Fachin ${ }^{2}$, Valdir Zucareli ${ }^{2}$ \\ ${ }^{1}$ Centro Universitário da Grande Dourados - UNIGRAN, Dourados, MS. E-mail: zampar_@hotmail.com \\ ${ }^{2}$ Universidade Estadual de Maringá, Campus Regional de Umuarama - CAU/UEM, Umuarama, PR.
}

\section{RESUMO}

O objetivo deste trabalho foi avaliar o efeito da aplicação de doses crescentes de bioestimulante na qualidade fisiológica de sementes esverdeadas de soja. A aplicação de bioestimulante não influencia na germinação de sementes esverdeadas de soja. $\mathrm{O}$ comprimento das plântulas de soja é incrementado pela aplicação de doses crescentes de bioestimulante, mas os ganhos são mais acentuados em amostras com proporções reduzidas de sementes esverdeadas.

Palavras-chave: Sementes, bioestimulante, Glycine max, reguladores vegetais, mudas

\section{PHYSIOLOGICAL QUALITY OF BIOSTIMULANT TREATED GREEN SOYBEAN SEEDS}

\begin{abstract}
The aim of this study was to evaluate the effect of increasing doses of biostimulant on physiological quality of green soybean seeds. The application of biostimulant does not influence germination of green soybean. Soybean seedling length increased with the application of higher bioestimulant doses, but differences are accentuated in samples with lower proportions of green seeds.
\end{abstract}

Keywords: Seeds, biostimulant, Glycine max, growth regulators, seedling

INTRODUÇÃO

A qualidade de sementes de soja [Glycine $\max$ (L.) Merrill], principalmente em regiões tropicais, pode ser influenciada por diversos fatores, que ocorrem antes e durante a colheita e em todas as demais etapas de produção. Dentre esses fatores destaca-se a deterioração por intempéries, que abrange, entre outras condições, períodos de seca, extremos de temperatura durante a maturação e fortes flutuações das condições de umidade relativa ambiente 


\section{QUALIDADE FISIOLÓGICA DE SEMENTES ESVERDEADAS DE SOJA TRATADAS COM \\ BIOESTIMULANTE}

(FRANÇA NETO et al., 2000). Esses fatores têm interferido na produção brasileira de soja, que tem sido afetada por um fenômeno também preocupante em outros países, a retenção de clorofila nas sementes. Os cotilédones apresentam vestígios do pigmento verde e a consequência verificada na produção de sementes é o decréscimo do vigor e da viabilidade (ZORATO et al. 2007).

Em circunstâncias normais de desenvolvimento, a planta de soja amadurece e a enzima clorofilase degrada a clorofila presente na semente, resultando na coloração característica de cada cultivar. Porém, em situações atípicas de clima quente e seco, durante os últimos estádios de maturação da semente, essa atividade é alterada. Acreditase que, com a morte prematura da planta e, consequentemente, a maturação forçada da semente, a atividade da enzima clorofilase cessa antes de toda a clorofila ser degradada (FRANÇA NETO et al., 2000). A semente de soja pode, ainda, apresentar a coloração esverdeada em decorrência de outros fatores, adicional às variações climáticas. Existem genótipos em cuja semente a clorofila é retida no tegumento, mesmo quando madura, devido a uma característica genética (PALMER \& KILEN, 1987).
Sementes esverdeadas apresentam alta fluorescência de clorofila (CÍCERO et al., 2009) e elevados índices de deterioração, que podem ocasionar a redução da germinação, do vigor e da viabilidade de lotes de soja (FRANÇA NETO et al., 2005). Trabalho efetuado por Medina et al. (1997) mostraram que a presença de sementes esverdeadas, detectadas em lotes de soja de bom padrão fisiológico, comprometeram a germinação de sementes de quatro cultivares. Mais recentemente, Rangel et al. (2011) constataram acréscimos dos percentuais de sementes esverdeadas provocando redução acentuada da germinação e do comprimento de raiz. Estudo de Zorato et al. (2007) também mostrou haver relação inversa entre o índice de sementes esverdeadas e a intensidade da tonalidade verde dos cotilédones com a qualidade fisiológica de sementes de soja. Pádua et al. (2007) constataram 9\% de sementes esverdeadas como a porcentagem segura para comercialização de lotes de soja e que estas sementes, em sua maioria, estão mortas ou originam plântulas anormais.

A utilização de bioestimulantes a fim de aperfeiçoar as produções em diversas culturas e é cada vez mais comum (DOURADO NETO et al., 2004). Segundo Weaver (1972), os bioestimulantes entram 
na classe dos reguladores vegetais que fazem a regulação ou aceleração de várias funções em diversos tecidos vegetais, dentre eles, os mais comuns são as auxinas, as citocininas, as giberilinas, os retardadores, os inibidores e o etileno. Como benefício da utilização dos bioestimulantes pode-se citar aumento do crescimento e do desenvolvimento vegetal, o que estimula a divisão, a diferenciação e o alongamento celular.

Vieira \& Castro (2001) estudaram o efeito de diferentes dosagens de bioestimulante nas culturas da soja e obteve aumentos expressivos sobre produtividade das plantas, quando o produto foi aplicado diretamente sobre as sementes. Segundo Cobucci et al. (2004) a aplicação de tais produtos via sementes ou foliar, inclusive, tem se tornado uma prática agrícola rotineira, juntamente com fungicidas e inseticidas.

Alleoni et al. (2000) relataram que a imersão de sementes em soluções com reguladores vegetais pode possibilitar a superação da dormência e aumentar a uniformidade na emergência das plântulas. Vieira \& Castro (2001) fizeram um estudo sobre diferentes dosagens de Stimulate ${ }^{\circledR}$ em sementes de soja e observou incremento na produtividade das plantas quando o produto foi aplicado diretamente nas sementes. O mesmo autor relatou que a aplicação do produto às sementes resultou em aumento no crescimento das raízes, no desenvolvimento de plântulas normais e na massa seca das plântulas.

Assim, o presente trabalho teve como objetivo avaliar os efeitos da aplicação de bioestimulante na qualidade fisiológica de sementes esverdeadas de soja.

\section{MATERIAL E MÉTODOS}

O presente trabalho foi realizado no Laboratório de Análise de Sementes da Universidade Estadual de Maringá, Campus Regional de Umuarama, na cidade de Umuarama-PR.

Foi utilizado um lote de sementes de soja, da cultivar Potência, produzidas na safra 2011/2012, na cidade de UmuaramaPR, em campo experimental do Instituto Agronômico do Paraná - IAPAR. O lote foi previamente selecionado quanto à presença de sementes esverdeadas, sendo retiradas cinco amostras de $300 \mathrm{~g}$ contendo apenas sementes de coloração amarela, características da cultivar. Sementes que apresentavam quaisquer tonalidades de verde em toda a extensão dos cotilédones (ZORATO et al., 2007) foram separadas e misturadas às amostras iniciais na proporção 


\section{QUALIDADE FISIOLÓGICA DE SEMENTES ESVERDEADAS DE SOJA TRATADAS COM \\ BIOESTIMULANTE}

de $0,5 \%, 10 \%, 15 \%, 20 \%$ de sementes esverdeadas.

Após a definição das porcentagens de sementes verdes, procederam-se as seguintes análises de caracterização das amostras:

Teor de água

Foram empregadas duas repetições de 20 sementes e o método da estufa elétrica de desidratação, sem ventilação forçada, a $105 \pm 3{ }^{\circ} \mathrm{C}$ durante 24 horas (BRASIL, 2009).

\section{Massa de cem sementes}

Foi realizada conforme adaptação de instruções de Brasil (2009), oito repetições de 100 sementes por tratamento foram contadas e tiveram suas massas determinadas; os resultados foram expressos em gramas.

\section{Condutividade elétrica}

Utilizou-se quatro repetições de 50 sementes por tratamento, com massas conhecidas, as quais foram imersas em 75 $\mathrm{mL}$ de água destilada em recipientes de plástico. Os recipientes foram mantidos em germinador regulado a $25^{\circ} \mathrm{C}$ por 24 horas para, a seguir, proceder-se a leitura com condutivímetro (VIEIRA \& KRZYZANOWSKI, 1999). O resultado foi expresso em $\mu \mathrm{S} \mathrm{cm}^{-1} \mathrm{~g}^{-1}$, dividindo-se a leitura pela massa das sementes.

Após as análises descritas, realizadas a fim de uniformizar as amostras e, desse modo, isolar efeitos dos tratamentos, procedeu-se a aplicação às sementes do bioestimulante Stimulate ${ }^{\circledR}(0,005 \%$ ácido 4 indol-3-ilbutírico $+0,005 \%$ ácido giberélico $+0,009 \%$ cinetina) nas doses $0 ; 2,5 ; 5$ e 10 $\mathrm{mL} \mathrm{kg}^{-1}$ de sementes. Imediatamente após a aplicação do produto, avaliou-se a germinação das sementes e o desenvolvimento das plântulas, por meio dos seguintes testes:

\section{Teste de germinação (Tg)}

Quatro repetições de 50 sementes por tratamento foram dispostas sobre papel toalha, umedecidos com água destilada em quantidade correspondente a 2,5 vezes a massa do papel seco. Os rolos permaneceram acondicionados em sacos plásticos fechados e mantidos em um germinador regulado à temperatura de $25^{\circ} \mathrm{C}$ por oito dias. No oitavo dia, foram computadas as porcentagens de plântulas normais e anormais.

\section{Primeira contagem do $\mathrm{Tg}$}

Considerado como teste de vigor, foi conduzido juntamente com o teste de germinação, avaliando-se as plântulas normais no quinto dia após a instalação do teste.

\section{Comprimento de plântulas}

Foi determinado com o emprego de quatro repetições de 10 sementes por 
tratamento dispostas sobre linha traçada no terço superior do papel, no sentido longitudinal. Os substratos foram umedecidos e preparados de maneira semelhante ao teste de germinação, na forma de rolos e mantidos, verticalmente, em germinador regulado a $25^{\circ} \mathrm{C}$ por cinco dias, na ausência de luz (NAKAGAWA, 1999). Decorrido este período, o comprimento da raiz primária e do hipocótilo foram medidos separadamente e o comprimento calculado pelo quociente entre a soma das medidas e o número de plântulas normais.

\section{Massa da matéria seca de plântulas}

Foi determinada utilizando-se as plântulas obtidas ao final do teste de comprimento de plântulas, as quais foram colocadas separadamente em sacos de papel e secas em estufa com circulação forçada de ar à temperatura de $80^{\circ} \mathrm{C}$, durante 24 horas. Os cálculos foram efetuados dividindo-se a massa obtida pelo número de plântulas contidas em cada rolo de papel (NAKAGAWA, 1999); com expressão dos resultados em mg por plântula.

Os dados foram submetidos à análise de variância com o auxílio do programa estatístico SISVAR (FERREIRA, 2011) e as médias comparadas pelo teste de Tukey $(p \leq 0,05)$ em esquema fatorial $4 \times 5$ (dose $x$ proporção de sementes esverdeadas na amostra).

\section{RESULTADOS E DISCUSSÃO}

As análises de caracterização inicial das amostras de soja, com diferentes proporções de sementes esverdeadas, revelaram uniformidade entre os tratamentos (Tabela 1). É importante que os lotes sejam homogêneos tendo em vista que os resultados de teor de água, massa e/ou condutividade elétrica podem interferir no tratamento com bioestimulante, principalmente em função da variação na quantidade de reserva disponível para germinação e permeabilidade do sistema de membranas nas células.

Uma possível explicação para esse fato seria que, segundo Bohner (2010), podem ser considerados dois tipos de soja verde. $\mathrm{O}$ primeiro caracteriza-se pela coloração verde na parte externa dos grãos, enquanto o interior permanece amarelo, sendo classificado como "grau 2". No outro tipo, a coloração verde é encontrada por todo o grão, classificado como "danificado". Além disso, os efeitos da retenção de clorofila na qualidade fisiológica de sementes de soja, têm sido mais frequentemente observados na germinação e no desenvolvimento de plântulas, como 


\section{QUALIDADE FISIOLÓGICA DE SEMENTES ESVERDEADAS DE SOJA TRATADAS COM \\ BIOESTIMULANTE}

constatado por Rangel et al. (2011). Os cotilédones, quando detentores de pigmento verde mais intenso são seriamente comprometidos, com grande quantidade de células deterioradas, o que pode provocar danos na translocação de reservas para o eixo embrionário no momento da germinação (ZORATO et al., 2007).

A germinação das sementes de soja, tanto na primeira como na última contagem, foi reduzida quanto maiores as proporções de sementes esverdeadas na amostra (Tabelas 2 e 3), não tendo sido constatado efeito da aplicação do bioestimulante. Notadamente, mesmo a presença de porcentagens reduzidas de sementes esverdeadas no lote ocasiona decréscimo na germinação, enquanto que somente maiores proporções ocasionaram redução da velocidade de germinação, avaliada pela primeira contagem do teste, corroborando com dados de Costa et al. (2001), que afirmaram que quanto maior a porcentagem de sementes esverdeadas no lote, mais baixos são os valores de germinação. Os autores descreveram que a germinação das sementes de soja foi reduzida linearmente com o aumento de sementes esverdeadas na amostra.

Os resultados desse trabalho são semelhantes aos obtidos por Zorato et al. (2007), onde se relata que a presença de sementes esverdeadas no lote interfere negativamente na qualidade. No entanto, no presente estudo, mesmo a proporção de $20 \%$ de sementes esverdeadas na amostra permitiu a obtenção de $80 \%$ de germinação, porcentagem mínima exigida para comercialização de sementes de soja (Brasil, 2005).

Tabela 1. Teor de água, massa e condutividade elétrica de amostras de soja com diferentes proporções de sementes esverdeadas.

\begin{tabular}{cccc}
\hline $\begin{array}{c}\text { Proporção de sementes } \\
\text { esverdeadas na amostra }\end{array}$ & $\begin{array}{c}\text { Teor de água } \\
\%\end{array}$ & $\begin{array}{c}\text { Massa de } 100 \text { sementes } \\
(\%)\end{array}$ & $\begin{array}{c}\text { Condutividade elétrica } \\
\mu \mathrm{S} \mathrm{cm}^{-1} \mathrm{~g}^{-1}\end{array}$ \\
\hline 0 & 11,7 & $12,44 \mathrm{a}^{(1)}$ & $133,05 \mathrm{a}$ \\
5 & 11,8 & $12,68 \mathrm{a}$ & $142,81 \mathrm{a}$ \\
10 & 11,9 & $12,85 \mathrm{a}$ & $171,13 \mathrm{a}$ \\
15 & 11,9 & $12,74 \mathrm{a}$ & $141,87 \mathrm{a}$ \\
20 & 11,8 & $12,49 \mathrm{a}$ & $169,32 \mathrm{a}$ \\
\hline $\mathrm{F}_{\text {calc }}$ & - & $2,779 \mathrm{~ns}$ & $3,318 \mathrm{~ns}$ \\
C.V. $(\%)$ & - & 2,31 & 12,60 \\
\hline
\end{tabular}

(1) Médias seguidas da mesma letra minúscula na coluna não diferem pelo teste de Tukey ( $\mathrm{p} \geq 0,05)$. ns: não significativo. 
Tabela 2. Germinação (\%) de sementes esverdeadas de soja tratadas com bioestimulante.

\begin{tabular}{|c|c|c|c|c|c|}
\hline \multirow{2}{*}{$\begin{array}{l}\text { Proporção de sementes } \\
\text { esverdeadas na amostra } \\
(\%)\end{array}$} & \multicolumn{4}{|c|}{ Dose $\left(\mathrm{mL} \mathrm{kg}^{-1}\right)$} & \multirow[b]{2}{*}{ Média } \\
\hline & 0 & 2,5 & 5,0 & 10 & \\
\hline 0 & 90 & 88 & 96 & 89 & $91 \mathrm{a}^{(\mathrm{I})}$ \\
\hline 5 & 88 & 80 & 84 & 88 & $85 \mathrm{~b}$ \\
\hline 10 & 83 & 89 & 83 & 82 & $84 \mathrm{~b}$ \\
\hline 15 & 84 & 85 & 78 & 79 & $81 \mathrm{~b}$ \\
\hline 20 & 81 & 82 & 79 & 79 & $80 \mathrm{~b}$ \\
\hline Média & 85 & 85 & 84 & 83 & - \\
\hline$F_{\text {calc }}$ propoções & & & $9,922 * *$ & & \\
\hline $\mathrm{F}_{\text {calc }}$ dose & & & $0,506 \mathrm{~ns}$ & & \\
\hline $\mathrm{F}_{\text {calc }}$ interação & & & $1,800 \mathrm{~ns}$ & & \\
\hline C.V. $(\%)$ & & & 6,14 & & \\
\hline
\end{tabular}

Tabela 3. Primeira contagem de germinação (\%) de sementes esverdeadas de soja tratadas com bioestimulante.

\begin{tabular}{|c|c|c|c|c|c|}
\hline \multirow{2}{*}{$\begin{array}{l}\text { Proporção de sementes } \\
\text { esverdeadas na amostra } \\
(\%)\end{array}$} & \multicolumn{4}{|c|}{ Dose $\left(\mathrm{mL} \mathrm{kg}^{-1}\right)$} & \multirow[b]{2}{*}{ Média } \\
\hline & 0 & 2,5 & 5,0 & 10 & \\
\hline 0 & 88 & 87 & 91 & 85 & $88 \mathrm{a}^{(1)}$ \\
\hline 5 & 88 & 80 & 81 & 85 & $83 a b$ \\
\hline 10 & 81 & 89 & 80 & 82 & $83 a b$ \\
\hline 15 & 77 & 74 & 71 & 77 & $74 \mathrm{c}$ \\
\hline 20 & 77 & 81 & 76 & 77 & $78 \mathrm{bc}$ \\
\hline Média & 82 & 82 & 80 & 81 & - \\
\hline $\mathrm{F}_{\text {calc }}$ propoções & & & $6,618^{*}$ & & \\
\hline $\mathrm{F}_{\text {calc }}$ dose & & & 0,407 & & \\
\hline $\mathrm{F}_{\text {calc }}$ interação & & & 0,695 & & \\
\hline C.V. $(\%)$ & & & 9,87 & & \\
\hline
\end{tabular}

Estudos sobre os efeitos de vários níveis de sementes esverdeadas sobre a qualidade fisiológica de lotes de diferentes cultivares de soja indicaram índices superiores a $10 \%$ como impossibilitadores da comercialização como semente fiscalizada (COSTA et al., 2001). Já Pádua et al. (2007) relataram um valor de $9 \%$ de sementes esverdeadas como a porcentagem segura para comercialização de lotes de soja e que estas sementes, em sua maioria, estão mortas ou originam plântulas anormais.

Nesse trabalho, a porcentagem de plântulas anormais foi variável com a 
interação entre os tratamentos aplicados, mas o número de plântulas de soja com alguma anormalidade encontrou-se próximo desse valor máximo de referência (Tabela 4). A ocorrência de plântulas anormais correlacionou-se significativamente e negativamente com a porcentagem de germinação $(-0,64 * *)$.

Os efeitos das doses crescentes de bioestimulante no comprimento das plântulas de soja foram variáveis e dependentes da proporção de sementes esverdeadas encontradas na amostra (Tabelas 5, 6 e 7).

De maneira geral, plântulas com maior comprimento da raiz primária, do hipocótilo e total foram produzidas com a maior dose de bioestimulante, independente da presença ou ausência de sementes esverdeadas na amostra. Nota-se, adicionalmente, que o aumento no comprimento é menos acentuado em amostras com maiores proporções de sementes esverdeadas, o que demonstra o potencial de utilização do produto em lotes com menor ocorrência dessas sementes. O comprimento da raiz primária foi $o$ parâmetro que apresentou incrementos mais acentuados com a aplicação do bioestimulante. Santos \& Vieira (2005) encontraram efeito significativo da aplicação de doses de bioestimulante via semente no comprimento das raízes do algodoeiro, com incremento de $45,5 \%$ em relação ao controle.

Tabela 4. Plântulas anormais ${ }^{(1)}$ (\%) avaliadas no teste de germinação de sementes esverdeadas de soja tratadas com bioestimulante.

\begin{tabular}{|c|c|c|c|c|c|}
\hline \multirow{2}{*}{$\begin{array}{c}\text { Proporção de sementes } \\
\text { esverdeadas na amostra }(\%)\end{array}$} & \multicolumn{4}{|c|}{ Dose $\left(\mathrm{mL} \mathrm{kg}^{-1}\right)$} & \multirow[b]{2}{*}{ Média } \\
\hline & 0 & 2,5 & 5,0 & 10 & \\
\hline 0 & $7 \mathrm{Ba}^{(2)}$ & $9 \mathrm{Ba}$ & $3 \mathrm{Ab}$ & $5 \mathrm{ABa}$ & 6 \\
\hline 5 & $6 \mathrm{Aa}$ & $8 \mathrm{Aa}$ & $5 \mathrm{Aab}$ & $5 \mathrm{Aa}$ & 6 \\
\hline 10 & $13 \mathrm{Ba}$ & $5 \mathrm{Aa}$ & $11 \mathrm{ABa}$ & $6 \mathrm{ABa}$ & 8 \\
\hline 15 & $7 \mathrm{ABa}$ & $5 \mathrm{Aa}$ & $12 \mathrm{Ba}$ & $10 \mathrm{ABa}$ & 8 \\
\hline 20 & $8 \mathrm{Aa}$ & $8 \mathrm{Aa}$ & $10 \mathrm{Aa}$ & $13 \mathrm{Aa}$ & 9 \\
\hline Média & 8 & 7 & 8 & 8 & - \\
\hline $\mathrm{F}_{\text {calc }}$ propoções & & & $3,279 *$ & & \\
\hline $\mathrm{F}_{\text {calc }}$ dose & & & $0,714 \mathrm{~ns}$ & & \\
\hline $\mathrm{F}_{\text {calc }}$ interação & & & $2,692 * *$ & & \\
\hline C.V. $(\%)$ & & & 9,14 & & \\
\hline
\end{tabular}

${ }^{(1)}$ Dados transformados em arcsen $\sqrt{\mathrm{x}} / 100+0,5$.

(2) Médias seguidas da mesma letra minúscula na coluna e maiúscula na linha não diferem pelo teste de Tukey $(\mathrm{p} \geq 0,05) .{ }^{*} \mathrm{e}^{* *}$ significativo a 5 e $1 \%$ de probabilidade, respectivamente; ns: não significativo. 
Tabela 5. Comprimento da raiz primária $(\mathrm{cm})$ de plântulas produzidas por sementes esverdeadas de soja tratadas com bioestimulante.

\begin{tabular}{cccccc}
\hline $\begin{array}{c}\text { Proporção de sementes } \\
\text { esverdeadas na amostra }\end{array}$ & 0 & 2,5 & 5,0 & 10 & Média \\
$(\%)$ & & & & & \\
\hline 0 & $9,72 \mathrm{Cb}^{(1)}$ & $14,10 \mathrm{Ba}$ & $19,80 \mathrm{Aa}$ & $19,57 \mathrm{Aa}$ & 15,80 \\
5 & $12,64 \mathrm{Bab}$ & $14,11 \mathrm{Ba}$ & $18,83 \mathrm{Aab}$ & $19,73 \mathrm{Aa}$ & 16,32 \\
10 & $10,44 \mathrm{Cab}$ & $14,53 \mathrm{Ba}$ & $14,77 \mathrm{ABc}$ & $17,51 \mathrm{Aa}$ & 14,31 \\
15 & $13,11 \mathrm{Ba}$ & $15,22 \mathrm{ABa}$ & $17,84 \mathrm{Aab}$ & $17,40 \mathrm{Aa}$ & 15,89 \\
20 & $12,22 \mathrm{Cab}$ & $14,18 \mathrm{BCa}$ & $16,12 \mathrm{ABbc}$ & $18,94 \mathrm{Aa}$ & 15,36 \\
\hline Média & 11,62 & 14,43 & 17,47 & 18,63 & - \\
\hline $\mathrm{F}_{\text {calc }}$ propoções & & & $3,954^{* *}$ & & \\
$\mathrm{~F}_{\text {calc dose }}$ & & & $83,932^{* *}$ & & \\
$\mathrm{~F}_{\text {calc }}$ interação & & $3,040^{* *}$ & & \\
C.V. $(\%)$ & & 9,91 & & \\
\hline
\end{tabular}

(1) Médias seguidas da mesma letra minúscula na coluna e maiúscula na linha não diferem pelo teste de Tukey $(\mathrm{p} \geq 0,05)$. ${ }^{*}$ significativo a $1 \%$ de probabilidade.

Tabela 6. Comprimento do hipocótilo $(\mathrm{cm})$ de plântulas produzidas por sementes esverdeadas de soja tratadas com bioestimulante.

\begin{tabular}{|c|c|c|c|c|c|}
\hline \multirow{2}{*}{$\begin{array}{l}\text { Proporção de sementes } \\
\text { esverdeadas na amostra } \\
(\%)\end{array}$} & \multicolumn{4}{|c|}{ Dose $\left(\mathrm{mL} \mathrm{kg}^{-1}\right)$} & \multirow[b]{2}{*}{ Média } \\
\hline & 0 & 2,5 & 5,0 & 10 & \\
\hline 0 & $8,32 \mathrm{Bab}^{(1)}$ & $9,82 \mathrm{Bab}$ & $13,12 \mathrm{Aab}$ & $14,03 \mathrm{Aab}$ & 11,32 \\
\hline 5 & $10,15 \mathrm{Ba}$ & $8,60 \mathrm{Bab}$ & $14,29 \mathrm{Aa}$ & $16,13 \mathrm{Aa}$ & 12,29 \\
\hline 10 & $6,08 \mathrm{Cb}$ & $8,50 \mathrm{Bb}$ & $10,76 \mathrm{ABb}$ & $11,70 \mathrm{Ab}$ & 9,26 \\
\hline 15 & $9,41 \mathrm{Ba}$ & $11,07 \mathrm{ABa}$ & $11,64 \mathrm{ABb}$ & $12,88 \mathrm{Ab}$ & 11,25 \\
\hline 20 & 8,53 Bab & $10,99 \mathrm{Aab}$ & $11,74 \mathrm{Ab}$ & $13,11 \mathrm{Ab}$ & 11,09 \\
\hline Média & 8,50 & 9,79 & 12,31 & 13,57 & - \\
\hline $\mathrm{F}_{\text {calc }}$ propoções & & & $12,211^{* *}$ & & \\
\hline $\mathrm{F}_{\text {calc }}$ dose & & & $66,919 * *$ & & \\
\hline $\mathrm{F}_{\text {calc }}$ interação & & & $3,100 * *$ & & \\
\hline C.V. $(\%)$ & & & 11,44 & & \\
\hline
\end{tabular}


Tabela 7. Comprimento total $(\mathrm{cm})$ de plântulas produzidas por sementes esverdeadas de soja tratadas com bioestimulante.

\begin{tabular}{cccccc}
\hline $\begin{array}{c}\text { Proporção de sementes } \\
\text { esverdeadas na amostra }\end{array}$ & 0 & 2,5 & 5,0 & 10 & Média \\
$(\%)$ & $18,04 \mathrm{Cab}^{(1)}$ & $23,92 \mathrm{Ba}$ & $32,93 \mathrm{Aa}$ & $33,60 \mathrm{Aab}$ & 27,12 \\
0 & $22,79 \mathrm{Ba}$ & $22,71 \mathrm{Ba}$ & $33,12 \mathrm{Aa}$ & $35,85 \mathrm{Aa}$ & 28,62 \\
5 & $16,51 \mathrm{Cb}$ & $23,03 \mathrm{Ba}$ & $25,53 \mathrm{ABb}$ & $29,21 \mathrm{Ab}$ & 23,57 \\
10 & $22,53 \mathrm{Ba}$ & $26,29 \mathrm{ABa}$ & $29,47 \mathrm{Aab}$ & $30,28 \mathrm{Ab}$ & 27,14 \\
15 & $20,75 \mathrm{Cab}$ & $25,16 \mathrm{BCa}$ & $27,87 \mathrm{ABb}$ & $32,05 \mathrm{Aab}$ & 26,46 \\
20 & 20,12 & 24,22 & 29,78 & 32,20 & - \\
\hline Média & \multicolumn{5}{c}{$9,230^{* *}$} \\
$\mathrm{~F}_{\text {calc }}$ propoções & \multicolumn{5}{c}{$99,081^{* *}$} \\
$\mathrm{~F}_{\text {calc dose }}$ do & $3,063^{* *}$ \\
$\mathrm{~F}_{\text {calc }}$ interação & \multicolumn{5}{c}{9,21} \\
C.V. $(\%)$ &
\end{tabular}

(1) Médias seguidas da mesma letra minúscula na coluna e maiúscula na linha não diferem pelo teste de Tukey $(\mathrm{p} \geq 0,05) . * *$ significativo a $1 \%$ de probabilidade.

Resultados semelhantes foram encontrados por Vieira \& Castro (2001), cujo estudo revelou que as doses de 2,6 e 7,4 $\mathrm{mL} \mathrm{kg}^{-1}$ de bioestimulante proporcionaram resultados de desenvolvimento da raiz primária com 9,9 e $0,8 \%$ de aumento em relação à testemunha.

Apesar dos resultados encontrados na literatura referirem-se aos efeitos mais acentuados da aplicação de reguladores vegetais no desenvolvimento da raiz primária (VIEIRA \& CASTRO, 2001; SANTOS \& VIEIRA, 2005), o aumento no comprimento do hipocótilo decorrente da aplicação de doses crescentes de bioestimulante também foi observado no presente trabalho.

Zorato et al. (2007) observaram, visualmente, prejuízo no desenvolvimento de plântulas oriundas de lotes com maior porcentagem de sementes de pigmentação verde. Sementes com cotilédones esverdeados podem apresentar efeitos deletérios causados por deterioração advinda da não-degradação de cloropigmentos, que, de acordo com Fukushima \& LanferMarquez (2000), são suscetíveis a muitas reações de degradações, como epimerização, pirólise, hidroxilação, oxidação, fotoxidação ou feofitinização. No entanto, observou-se no presente trabalho, variação nos resultados de desenvolvimento das plantas não somente em razão da proporção de sementes esverdeadas na amostra, mas também, em função da dose aplicada de bioestimulante.

A separação visual das sementes esverdeadas pode ter ocasionado tais variações, uma vez que sementes com a 
menor quantidade de fluorescência da clorofila apresentam maior qualidade (JALINK et al., 1998). Segundo Teixeira et al. (2011), apesar de vários estudos indicarem a relação negativa entre a presença de sementes esverdeadas e a qualidade de lotes de soja, ainda não existem informações claras sobre o efeito da clorofila, pigmento que confere essa coloração às sementes.

A massa da matéria seca das plântulas de soja não foi influenciada pela aplicação das doses de bioestimulante, com exceção da amostra com $5 \%$ de sementes esverdeadas (Tabela 8). Devido à interação significativa entre os fatores, observou-se, somente após a aplicação de $5,0 \mathrm{~mL} \mathrm{~kg}^{-1}$, plântulas com maior massa provenientes de sementes dessa amostra.

Nota-se, de maneira geral, que as menores proporções de sementes esverdeadas na amostra não refletem em maior desenvolvimento das plântulas. No entanto, há produção de plântulas com maior comprimento após o tratamento das sementes de soja com o bioestimulante, mesmo amostras com proporções elevadas de sementes esverdeadas.

Vieira \& Castro (2001), utilizando o mesmo bioestimulante, encontraram um aumento de 55,3\% na matéria seca de plântulas de soja com a dose de $8 \mathrm{~mL} \mathrm{~kg}^{-1}$, resultado esse que se manteve estável até a dose de $10 \mathrm{~mL} \mathrm{~kg}^{-1}$.

Segundo Arteka (1996), as substâncias reguladoras do crescimento podem trabalhar sozinhas ou em combinação com outras, como se verifica no caso dos bioestimulantes durante o processo de germinação de sementes e também, nos eventos pós-germinativos, como a mobilização de reservas.

As giberelinas podem ser fundamentalmente exigidas na germinação de sementes para as etapas de ativação do crescimento vegetativo do embrião, enfraquecimento da camada do endosperma que envolve o embrião, que restringe seu crescimento, assim como na mobilização de reservas energéticas (TAIZ \& ZEIGER, 2013).

De acordo com Horcat \& Letham (1990), as citocininas estão envolvidas na germinação de sementes e nos rápidos eventos pós-germinativos, pois as citocininas endógenas podem ter papel na promoção do crescimento da radícula. Taiz \& Zeiger (2013) relataram, ainda, que sua função na germinação é regular o nível de inibidores ativos presentes nas sementes, permitindo que se tornem mais sensíveis à ação das giberelinas. 
Tabela 8. Massa da matéria seca (mg) de plântulas produzidas por sementes esverdeadas de soja tratadas com bioestimulante.

\begin{tabular}{|c|c|c|c|c|c|}
\hline \multirow{2}{*}{$\begin{array}{c}\text { Proporção de sementes } \\
\text { esverdeadas na amostra } \\
(\%)\end{array}$} & \multicolumn{4}{|c|}{ Dose $\left(\mathrm{mL} \mathrm{kg}^{-1}\right)$} & \multirow[b]{2}{*}{ Média } \\
\hline & 0 & 2,5 & 5,0 & 10 & \\
\hline 0 & $17,37 \mathrm{Aa}$ & $24,10 \mathrm{Aa}$ & $21,27 \mathrm{Ab}$ & $26,63 \mathrm{Aa}$ & 22,34 \\
\hline 5 & $23,47 \mathrm{Ba}$ & $26,45 \mathrm{ABa}$ & $36,00 \mathrm{Aa}$ & $21,42 \mathrm{Ba}$ & 26,83 \\
\hline 10 & $25,95 \mathrm{Aa}$ & $27,39 \mathrm{Aa}$ & $23,53 \mathrm{Ab}$ & $26,20 \mathrm{Aa}$ & 25,77 \\
\hline 15 & $19,21 \mathrm{Aa}$ & $19,53 \mathrm{Aa}$ & $19,37 \mathrm{Ab}$ & $22,32 \mathrm{Aa}$ & 20,11 \\
\hline 20 & $16,31 \mathrm{Aa}$ & $19,50 \mathrm{Aa}$ & $23,16 \mathrm{Ab}$ & $26,67 \mathrm{Aa}$ & 21,41 \\
\hline Média & 20,46 & 23,39 & 24,67 & 24,65 & - \\
\hline $\mathrm{F}_{\text {calc }}$ propoções & & & $4,185^{* *}$ & & \\
\hline $\mathrm{F}_{\text {calc }}$ dose & & & $2,463 \mathrm{~ns}$ & & \\
\hline $\mathrm{F}_{\text {calc }}$ interação & & & $1,973 *$ & & \\
\hline C.V. $(\%)$ & & & 24,21 & & \\
\hline
\end{tabular}

Médias seguidas da mesma letra minúscula na coluna e maiúscula na linha não diferem pelo teste de Tukey $(\mathrm{p} \geq 0,05) .{ }^{*} \mathrm{e}^{* *}$ significativo a 5 e $1 \%$ de probabilidade, respectivamente; ns: não significativo.

\section{CONCLUSÕES}

A aplicação de bioestimulante não influencia a germinação de sementes esverdeadas de soja, mas somente o acréscimo nas proporções de sementes esverdeadas na amostra.

O comprimento das plântulas de soja é incrementado pela aplicação de doses crescentes de bioestimulante, mas os ganhos são mais acentuados em amostras com proporções reduzidas de sementes esverdeadas.

\section{REFERÊNCIAS BIBLIOGRÁFICAS}

ALLEONI, B.; BOSQUEIRO, M.; ROSSI, M. 2000. Efeito dos reguladores vegetais de Stimulate ${ }^{\circledR}$ no desenvolvimento e produtividade do feijoeiro (Phaseolus vulgaris L.) Publicatio UEPG Ciências Exatas e da Terra, Ciências Agrárias e Engenharias, Ponta Grossa, v.6, n.1, p.23-35.

ARTEKA, R. N. 1995. Plant growth substances: principles and applications. New York: Champman \& Hall. 332p.

BOHNER, H. 2002. Green soybeans. Disponível em: <http://www.omafra.gov. on.ca/english/crops/field/news/croptalk/2 002/ct_1102a2.htm>. Acesso em: 26 mar. 2010.

BRASIL. Ministério de Agricultura, Pecuária e Abastecimento. 2005. Padrões para produção e comercialização de sementes de soja. Anexo IX. Instrução normativa $n^{\circ} 25$, de 16 de dezembro de 2005. Seção 1, p.18.

BRASIL. Ministério da Agricultura, Pecuária e Abastecimento. 2009. Regras para análise de sementes. Brasília: MAPA/ACS. 395p.

CICERO, S.M.; SCHOOR, R.V.D.; JALINK, H. 2009. Use of chlorophyll fluorescence sorting to improve soybean seed quality. Revista Brasileira de 
Sementes, Londrina, v.31, n.4, p.145151.

COBUCCI, T.; WRUCK, F.J.; SILVA, J.G. 2005. Resposta do feijoeiro (Phaseolus vulgaris L.) às aplicações de bioestimulante e complexos nutritivos. In: CONGRESSO NACIONAL DE PESQUISA DE FEIJÃO, 8., Goiânia, 2005. Anais. Santo Antônio de Goiás: Embrapa Arroz e Feijão. p.1078-1081.

COSTA, N.P.; FRANÇA-NETO, J.B.; PEREIRA, J.E.; MESQUITA, C.M.; KRZYZANOWSKI, F.C.; HENNING, A.A. 2001. Efeito de sementes verdes na qualidade fisiológica de sementes de soja. Revista Brasileira de Sementes, Pelotas, v.23, n.2, p.102-107.

DOURADO NETO, D.; DARIO, G.J.A.; VIEIRA JÚNIOR, P.A.; MANFRON, P.A.; MARTIN, T.N.; BONNECARRÉRE, R.A.G.; CRESPO, P.E.N. 2004. Aplicação e influência do fitorregulador no crescimento das plantas de milho. Revista da Faculdade de Zootecnia, Veterinária e Agronomia, Uruguaiana, v.11, p.93-102.

FERREIRA, D.F. 2011. Sisvar: a computer statistical analysis system. Ciência e Agrotecnologia, Lavras, v.35, n.6, p.1039-1042.

FRANÇA-NETO, J.B.; KRZYZANOWSKI, F.C.; HENNING, A.A.; COSTA, N.P. 2000. Tecnologia de produção de sementes. In: Embrapa Soja. A cultura da soja no Brasil. Londrina: Embrapa Soja. CD-ROM.

FRANÇA-NETO, J.B.; PÁDUA, G.P.; CARVALHO, M.L.M.; COSTA, O.; BRUMATTI, P.S.R.; KRZYZANOWSKI, F.C.; COSTA, N.P.; HENNING, A.A.; SANCHES, D.P. 2005. Semente esverdeada de soja e sua qualidade fisiológica. Londrina: Embrapa Soja. 4p.

FUKUSHIMA, P.S.; LANFER-MARQUEZ, U.M. 2000. Chlorophyll derivates of soybean during maturation and drying conditions. In: INTERNATIONAL SOYBEAN PROCESSING AND UTILIZATION CONFERENCE, 3., Tukuba, 2000. Proceedings. Tukuba: Korin. p.87-88.

HORCAT, C.H.; LETHAM, D.S. 1990. Biosynthesis of cytokinin in germination seeds of Zea mays. Journal of Experimental Botany, v.41, p.15251528.

JALINK， H.; SCHOOR， R.V.D.; FRANDAS, A.; PIJLEN, J.G.V.; BINO, R.J. 1998. Chlorophyll fluorescence of Brassica oleraceae seeds as a nondestructive marker for seed maturity and seed performance. Seed Science Research, New York, v.8, n.4, p.437443.

MEDINA, P.F.; LAGO, A.A.; RAZERA, L.F.; MAEDA, J.A. 1997. Composição física e qualidade de lotes de sementes de soja com incidência de sementes esverdeadas. Informativo ABRATES, Londrina, v.7, n.1/2, p.36.

NAKAGAWA，J. 1999. Testes de vigor baseados no desempenho das plântulas. In: KRZYZANOWSKI, F.C.; VIEIRA, R.D.; FRANÇA NETO, J.B. (Eds.). Vigor de sementes: conceitos e testes. Londrina: ABRATES. cap.2, p.2-24.

PÁDUA, G.P.; FRANÇA NETO, J.B.; CARVALHO, M.L.M.; COSTA, O.; KRZYZANOWSKI, F.C.; COSTA, N.P. 2007. Tolerance level of green seed in soybean lots after storage. Revista Brasileira de Sementes, Londrina, v.29, n.3, p.112-120.

PALMER, R.G.; KILEN, T.C. 1987. Qualitative genetics and cytogenetics. In: WILCOX, J.R. (Ed.) Soybeans: improvement, production, and uses. Madison: American Society of Agronomy. p.135-209.

RANGEL, M.A.S.; MINUZZI, A.; PIEREZAN, L.; TEODÓSIO, T.K.C.; ONO, F.B.; CARDOSO, P.C. 2011. Presença e qualidade de sementes 
esverdeadas de soja na região sul do estado do Mato Grosso do Sul. Revista Brasileira de Sementes, Londrina, v.33, n.1, p.127-132.

SANTOS, C.M.G.; VIEIRA, E.L. 2005. Efeito de bioestimulante na germinação de sementes, vigor de plântulas e crescimento inicial do algodoeiro. Magistra, Cruz das Almas, v.17, n.3, p.124-130, 2005.

TAIZ, L.; ZEIGER, E. Fisiologia vegetal. 5ed. Porto Alegre: Artmed, 2013. 820p.

TEIXEIRA, R. N.; CAVARIANI, C.; FRANÇA-NETO, J. B.; BALDINI, L. S.; ROSSI, R. F.; NAKAGAWA, J. 2011. Porcentagem de sementes verdes, teor de clorofila e qualidade de lotes de soja. Informativo ABRATES, Londrina, v.21, n.2, p.39.

VIEIRA, E.L.; CASTRO, P.R.C. 2001. Ação de bioestimulante na germinação de sementes, vigor das plântulas, crescimento radicular e produtividade de soja. Revista Brasileira de Sementes, Pelotas, v.23, n.2, p.222-228.

VIEIRA, R.D.; KRZYZANOWSKI, F.C. 1999. Teste de condutividade elétrica. In: KRZYZANOWSKI, F.C.; VIEIRA, R.D.; FRANÇA NETO, J.B. (Eds.). Vigor de sementes: conceitos e testes. Londrina: ABRATES. p.1-26.

WEAVER, R.J. 1972. Plant growth substances in agriculture. San Francisco: W.H. Freeman. 594p.

ZORATO, M.F.; PESKE, S.T.; TAKEDA, C.; FRANÇA NETO, J.B. 2007. Presença de sementes esverdeadas em soja e seus efeitos sobre seu potencial fisiológico. Revista Brasileira de Sementes, Londrina, v.29, n.1, p.11-19. 